\title{
Influence of Low Ti-Element Additions on The Microstructure, Melting Properties and Creep Behavior of Sn-Ag-Cu Lead Free Solders
}

\author{
A.M. Yassin \\ amalyassin477@gmail.com \\ R. Afify Ismail \\ Redaafify@sci.asu.edu.eg \\ B.A. Khalifa \\ b.khalifa@ sci.asu.edu.eg
}

\begin{abstract}
$\mathrm{Sn}-3.5 \mathrm{wt} . \% \mathrm{Ag}-0.5 \mathrm{wt} . \% \mathrm{Cu}$ is one of the alloys considered for replacing $\mathrm{SnPb}$ solder alloys in electronic ambiance. In the present study, the effect of minor additions of Ti $(0.25,0.5,1.0 \mathrm{wt} . \%)$ on the microstructure, creep and thermal properties of Sn-3.5wt.\%Ag-0.5wt.\%Cu lead free solder alloy are investigated by means of scanning electron microscopy (SEM), $x$-ray diffraction (XRD), creep tests and differential scanning calorimetry (DSC) thermal tests. Results showed that the addition of different wt.\% of Ti refined the grain size of the solder alloys. The microstructure parameters obtained from $x$-ray analysis represented by lattice parameters $(a, c)$, axial ratio $(c / a)$, residual strains $\left(\Delta a / a_{0} \& \Delta c / c_{0}\right)$, peak height intensities and crystallite size of some crystallographic planes were found to be sensitive to $\mathrm{Ti}$ - additions, applied stresses and working temperatures. The morphological studies using SEM showed refinements of $\mathrm{Ag}_{3} \mathrm{Sn}_{1} \mathrm{Cu}_{6} \mathrm{Sn}_{5}$ and $\mathrm{Ti}_{2} \mathrm{Sn}_{3}(\mathrm{IMCs})$ in $\beta$-Sn matrix. Thermal analysis showed that $\mathrm{Ti}$ - additions slightly affect melting temperature and pastry range. In terms of creep behavior the addition of $1 \mathrm{wt} . \% \mathrm{Ti}$ gave the highest creep resistance with respect to the others, due to fine dispersion of IMCs. The stress exponents $(n)$ and the activation energies $(\mathrm{Q})$ indicated that the dominant creep mechanism is dislocation climb over all temperature ranges.
\end{abstract}

Keywords: SnAgCu lead free solder - Creep properties - Thermal properties - Microstructure - Ti\% addition Activation energy.

Date of Submission: 06 October, 2018

DOI: 10.24297/jap.v14i3.7834

ISSN: 2347-3487

Volume: 14 Issue: 3

Journal: Journal of Advances in Physics

Website: https://cirworld.com

This work is licensed under a Creative Commons Attribution 4.0 International License. 


\section{Introduction}

The progress of the electronic devices to reduce mobile thickness and size makes the industrial research looks for new Pb-free solders with good properties is an important issue. The SnAgCu solder alloy is considered to be one of the most promising candidate solders to replace SnPb owing to the consideration of the environment protection and human health. Therefore, enormous studies have been revealed that SnAgCu solder alloys are the best replacement for the conventional $\mathrm{SnPb}$ eutectic solder due to superior mechanical properties, low melting temperature and good solder abilities [1-3]. In order to enhance further properties of $\mathrm{SnAgCu}$ solder alloys, alloying elements such as transition metals, rare-earth and nano- particles were selected to add them into these alloys. $\mathrm{Pb}$ - free solder as an example is doped with nano-particles $\mathrm{TiO} 2$, non coarsening oxide dispersoid to provide high stability of microstructure and good mechanical properties than the confidential solders [4 -12]. The effect of nano-particle additions to the SnAgCu composite refined the IMCs and enhanced the mechanical properties [6-15]. Different attempts have been done to improve the properties of the $\mathrm{SnAgCu}$ solder alloys by adding minor alloying elements such as, $\mathrm{Ni}, \mathrm{Co}, \mathrm{Fe}, \mathrm{Zn}, \mathrm{Bi}, \mathrm{Sb}, \mathrm{Ge}$ or $\mathrm{Ti}$ [16-18 ] . Chenge et al. [18] found that the addition of Ni has small effect on the tensile strength. El-Daly et.al. [19] stated that the addition of $\mathrm{Ni}$ or $\mathrm{Sb}$ into $\mathrm{SnAgCu}$ improve the creep and thermal properties. The effect of $\mathrm{Zn}$ - element addition investigated by Gao. et al.[20] enhanced the wetability and decreased the under-cooling efficiency. It is well known that $\mathrm{Ti}$ - element is one of the most active transition metals [21]. Liu et. al. [22] have been added $\mathrm{Ti}$ to $\mathrm{SnAgCu}$ as a minor element to show its effect on the stress-strain experiments. They found some reducing in the elastic modulus of $\mathrm{SnAgCu}$. They presumed that Ti could be considered as the most promising candidate among other alloying elements. Ti-addition to $\mathrm{SnCu}$ and $\mathrm{SnAg}$ solders effectively reduce the under-cooling of solders. They also showed that; sever aging conditions caused coarsening the eutectic phase and the inter-metallic compound $\left(\mathrm{Ti}_{2} \mathrm{Sn}_{3}\right)$ stabilizes the morphology of - - $\mathrm{Sn}$ [23]. Chuang et al. [21] have been investigated the effect of adding a small amounts of $\mathrm{Ti}$ on the microstructure, hardness and stress-strain properties of $\mathrm{SnAgCu}$ solder. They indicated that adding a small amount of Ti has slight decrease in the melting temperature and refines the microstructure. They also showed that, the eutectic colony becomes narrower with the addition of Ti. In general they summarize that; the addition of Ti-element generates a new IMC $\left(\mathrm{Ti}_{2} \mathrm{Sn}_{3}\right)$; which enhanced the mechanical properties and made it a superior alloy than the free Ti- addition. The above-mentioned researches did not report any studies about creep properties of the superior alloy SnAgCu-x\%Ti; which is very important mechanical property for soldering. The adequate work of adding $\mathrm{Ti}$ - element on the creep behavior, microstructure, and thermal properties of $\mathrm{SnAgCu}$ lead free solder alloy leads to motivate the investigation of $\mathrm{Ti}$ addition. In the present work, we attempt to investigate the effect of minor-additions of $\mathrm{Ti}$ - element on the microstructure, creep and thermal properties of Sn-3.5wt.\%Ag- $0.5 \mathrm{wt}$.\%Cu solder alloy.

\section{Experimental Work}

Four different group of specimens Sn-3.5wt.\%Ag-0.5wt.\%Cu-xwt.\%Ti(x =0.00, 0.25, 0.5 and 1.0wt \%) denoted as S1, S2, S3, S4 lead free solders were prepared of high purity materials Sn, Ag, Cu and Ti (99.99\%). The specimens were prepared as previously described [24]. All components were melted in a graphite mould and the ingot was swaged to form wire specimens of $3 \mathrm{~cm}$ length and $0.7 \mathrm{~mm}$ diameter. The wire samples were then homogenized at $423 \mathrm{~K}$ for 2 hours then slowly cooled to room temperature to insure a uniform distribution of fully precipitated phases and free from any plastic strain accumulation. Computerized tensile testing machine was used to carry out the tensile creep tests. Creep tests have been done under different applied stresses in the range of $(13.4-33.8 \mathrm{MPa})$ and at different working temperatures (298 $-373 \mathrm{~K})$. An accuracy of $\pm 1^{\circ} \mathrm{C}$ was monitored by a thermocouple contacting the specimens. The structure of the original alloys S1, S2, S3, S4 lead free solders has been studied to show the effect of different amount of Ti - additions. The effect of working temperatures (298 - 373K) on the structure of one of the different alloys S4 (as an example) crept at constant applied stress (13.4 MPa) has been investigated. Philips X' Pert (MPD) goniometer PW3050/00 with graphite monochromatic using $\mathrm{Cu}-\mathrm{K}_{\alpha}$ target and $\mathrm{Ni}$ filter operated at (40 K.V.) and (30 mA) to give radiation of wavelength $(\lambda=0.15406 \mathrm{~nm}$ ) was used. Morphological appearance of the four original alloy samples (S1, S2, S3, S4) has been investigated by using SEM. The melting temperature of the solder plays a critical rule in soldering to ensure the process temperature of electronic products. To obtain the phenomena of melting 
process, Shimadzu DSC-50 differential scanning calorimeter was used for the original lead free solders (S1, S2, S3, S4). Heating the alloys in DSC was carried out at 10 degree/min. of heating rate in Nitrogen gas flow.

\section{Results and Discussion}

\section{1. Microstructure}

\subsubsection{Effect of Ti-addition on microstructure}

Fig.1(a) shows the x-ray diffraction patterns (XRD) of Sn-3.5wt.\%Ag-0.5wt.\%Cu (S1), Sn-3.5 wt.\%Ag-0.5 wt.\%Cu-0.25 wt.\%Ti (S2), Sn-3.5 wt.\%Ag-0.5 wt.\%Cu-0.5 wt.\%Ti (S3) and Sn-3.5 wt.\%Ag-0.5 wt.\%Cu-1.0 wt.\%Ti (S4) lead free solder alloys.

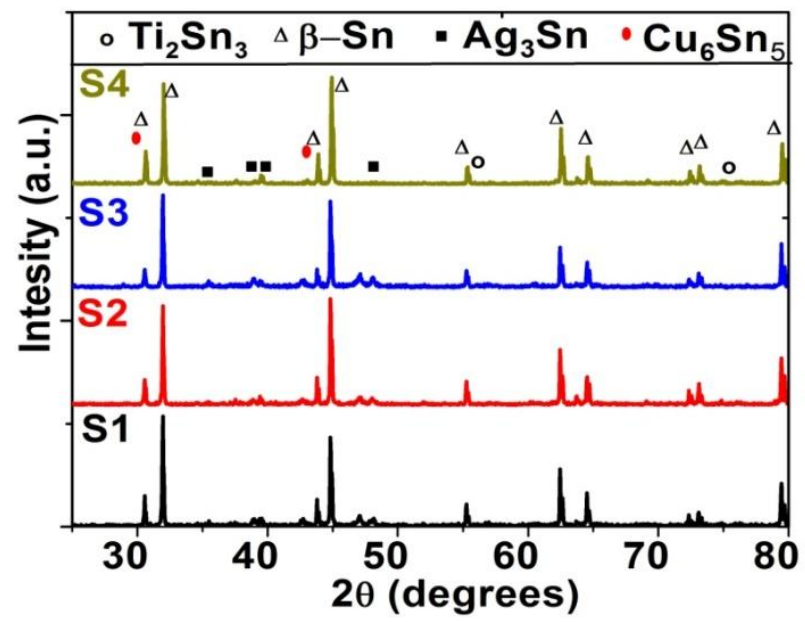

Figure 1(a): X - ray diffraction patterns for the solidified original alloys

$(\mathbf{S 1}, \mathbf{S 2}, \mathrm{S3}, \mathrm{S4})$

The microstructure of the four original wire alloys shows large peaks intensity of - $-\mathrm{Sn}$ rich phase and small peaks of $\mathrm{Ag}_{3} \mathrm{Sn}, \mathrm{Cu}_{6} \mathrm{Sn}_{5}$ and $\mathrm{Ti}_{2} \mathrm{Sn}_{3}$ (IMCs) phases. The lattice ${ }^{\text {parameters }}(\mathrm{a}, \mathrm{c})$ for all un-deformed original alloys $(\mathrm{S} 1, \mathrm{~S} 2, \mathrm{~S} 3, \mathrm{~S} 4)$ have been calculated using computer program. Fig. 1(b, c) show slight increase in a $(\mathrm{A})$ parameter and slight decrease in the $c(\mathrm{~A})$ parameter except for $0.5 \mathrm{wt}$.\%Ti-addition, the reverse is shown. The axial ratio (c/a) shows maximum increase by the addition of $0.5 \mathrm{wt} . \%$ Ti [Fig. 1 (d)].
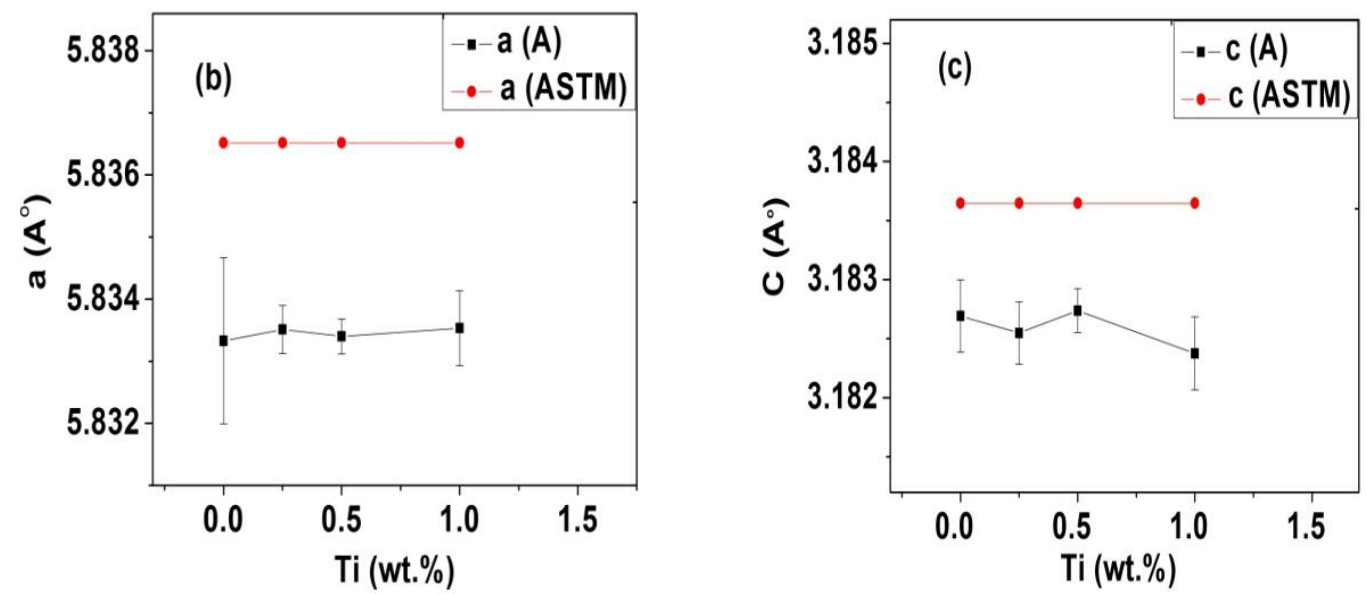


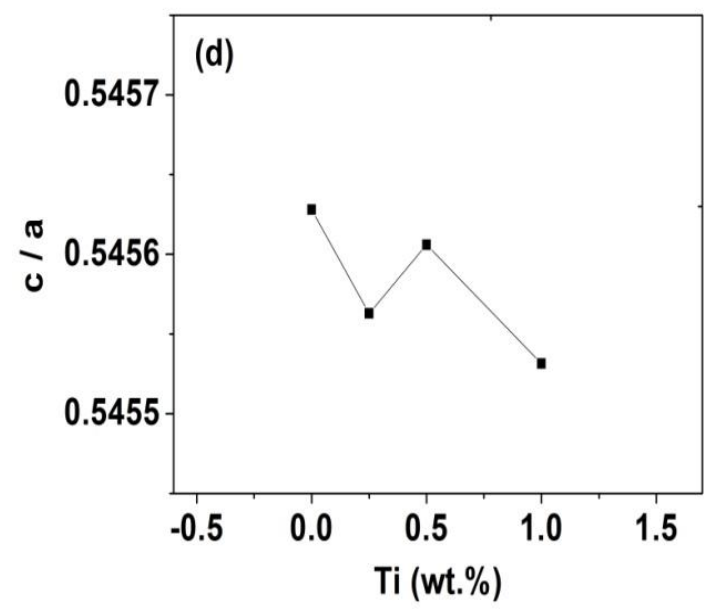

Figure 1(b,c,d) : The lattice parameters (a, c, c/a) for S1, S2, S3, S4 alloys as a function of Ti wt.\% additions

The peak height intensities of some crystallographic planes [(420)-(400) and (200)-(220)] are represented in Fig. $1(e, f)$. The crystallite size of the $x$-ray plane (211) is shown in Fig. $1(\mathrm{~g})$. All parameters show changes in case of 0.5 wt.\% Ti addition.
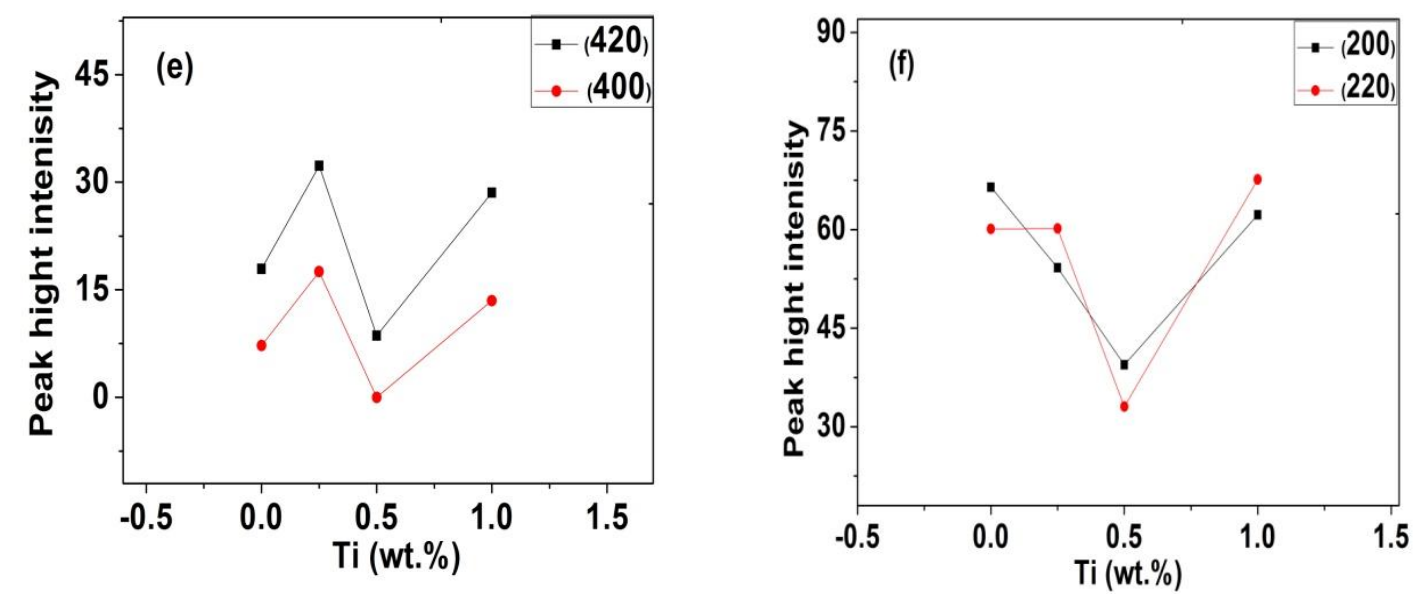

Figure 1(e,f): The intensities of crystallographic planes [(420)\&(400)], [(200)\&(220)] as a function of Ti wt.\% additions 


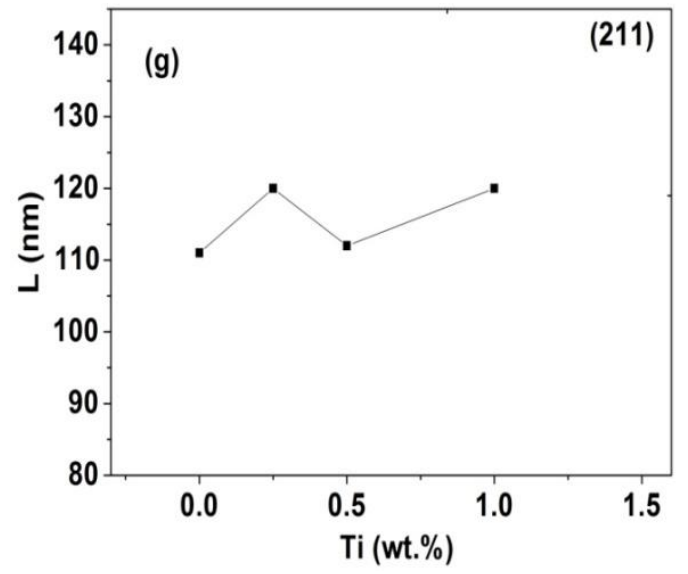

Figure 1(g): The crystallite size of the four alloys as a function of Ti wt. \% addition

\section{1.2. Effect of working temperature and stress deformation on microstructure}

Fig. 2(a) shows XRD patterns of S4 alloy samples crept at $13.4 \mathrm{MPa}$ and working temperatures $(298,333,353$ and 373K).

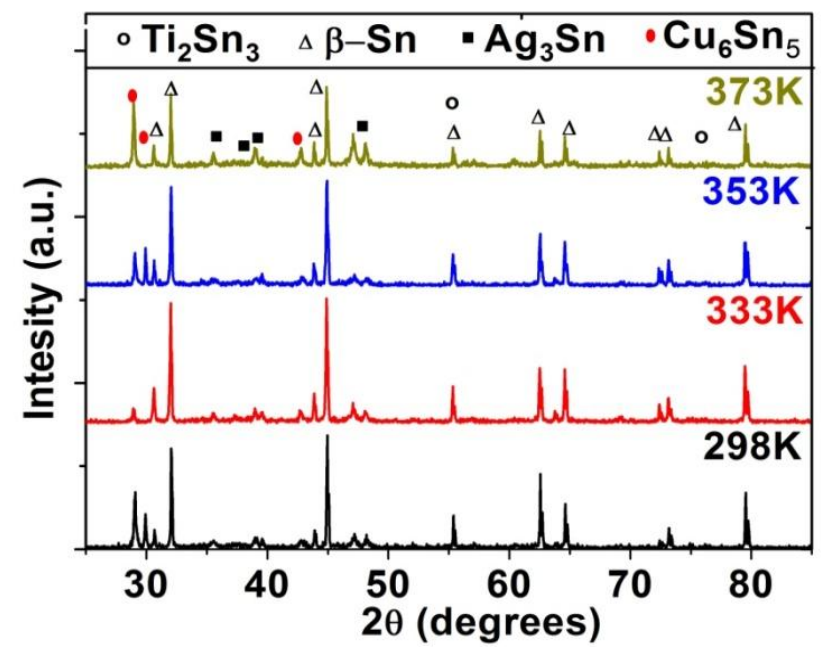

Figure 2(a): X-ray diffraction patterns for S4 alloy crept at $13.4 \mathrm{MPa}$ and different working temperatures.

The XRD parameters $\left(a, c, c / a, \cdot a / a_{0}\right.$ and $\left.\cdot c / c_{0}\right)$ are shown in Fig. 2(b-f). All XRD parameters show anomalous behavior at $353 \mathrm{~K}$ due to the increase of the amount of $\mathrm{Cu}_{6} \mathrm{Sn}_{5}$ (IMC); which is shown at $2 \cdot=29.06,29.94$ [Fig.2 (a)]. 

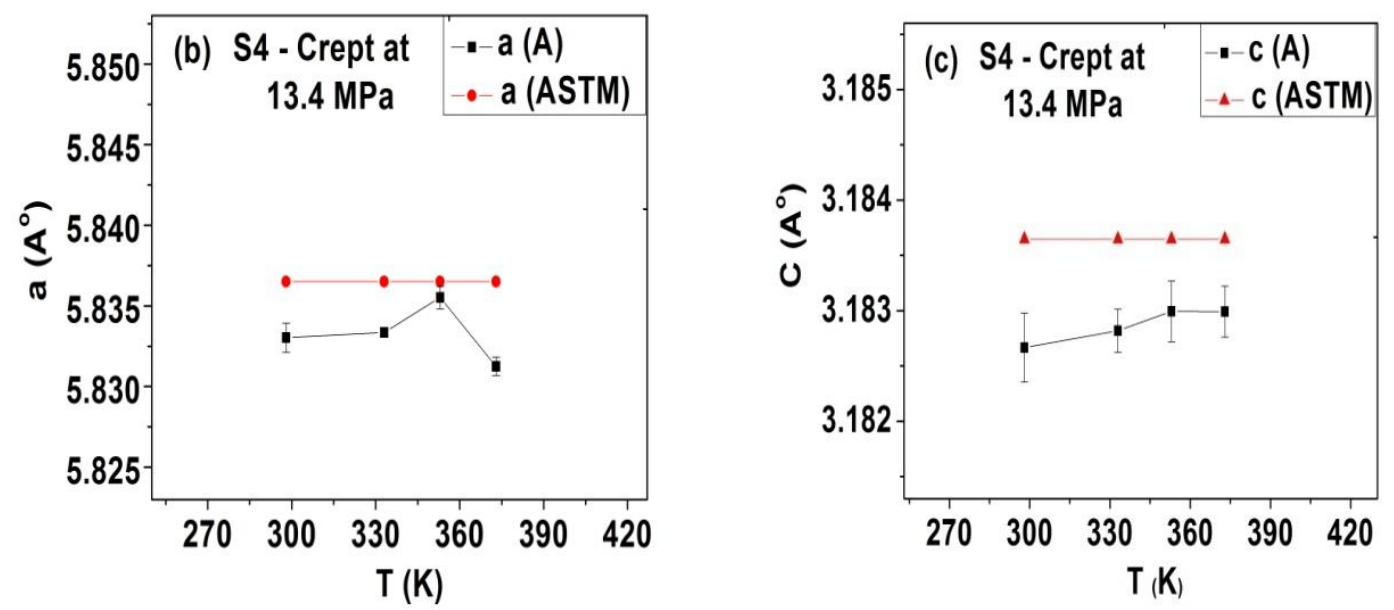

Figure 2(b,c)): The lattice parameters $(a, c)$ for $\mathrm{S} 4$ alloy deformed at $\cdot=13.4 \mathrm{MP}$ as a function of working temperatures
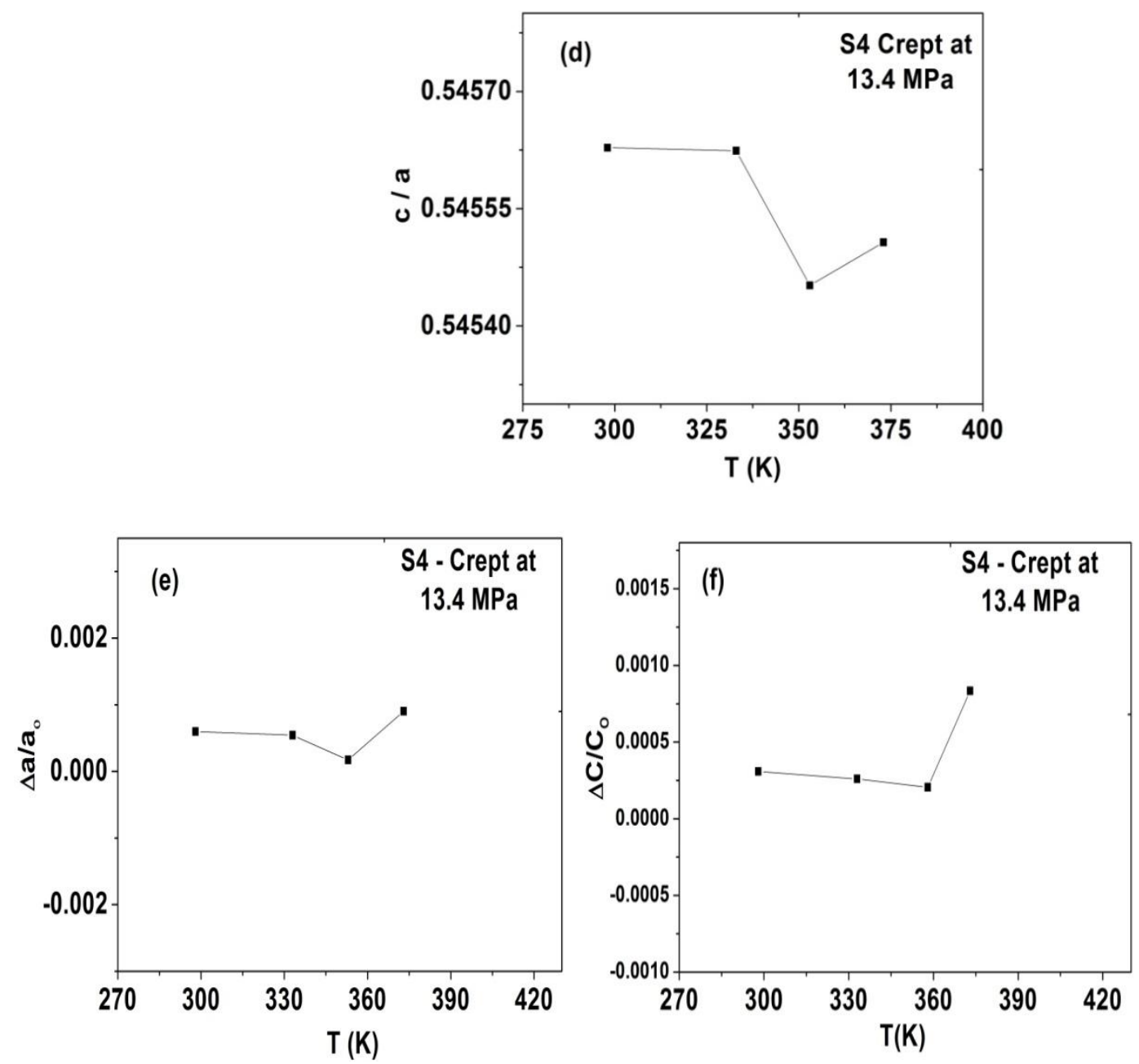

Figure $2(d, e, f)$ : The axial ratio $(c / a)$, the residual internal strains $\left(\Delta a / a_{0}, \Delta c / c_{0}\right)$ as a function of working temperatures. 
The peak height intensities of some crystallographic planes [(220)-(420) and (200)-(220)] are illustrated in Fig.2 $(\mathrm{g}, \mathrm{h})$. The apparent crystallite size $\mathrm{L}(\mathrm{nm})$ normal to the main reflection (211) after resolution of $\mathrm{K}$. . and $\mathrm{K}$. . intensities, which was calculated as in the previous work [24] and illustrated in Fig.2 (i, j).
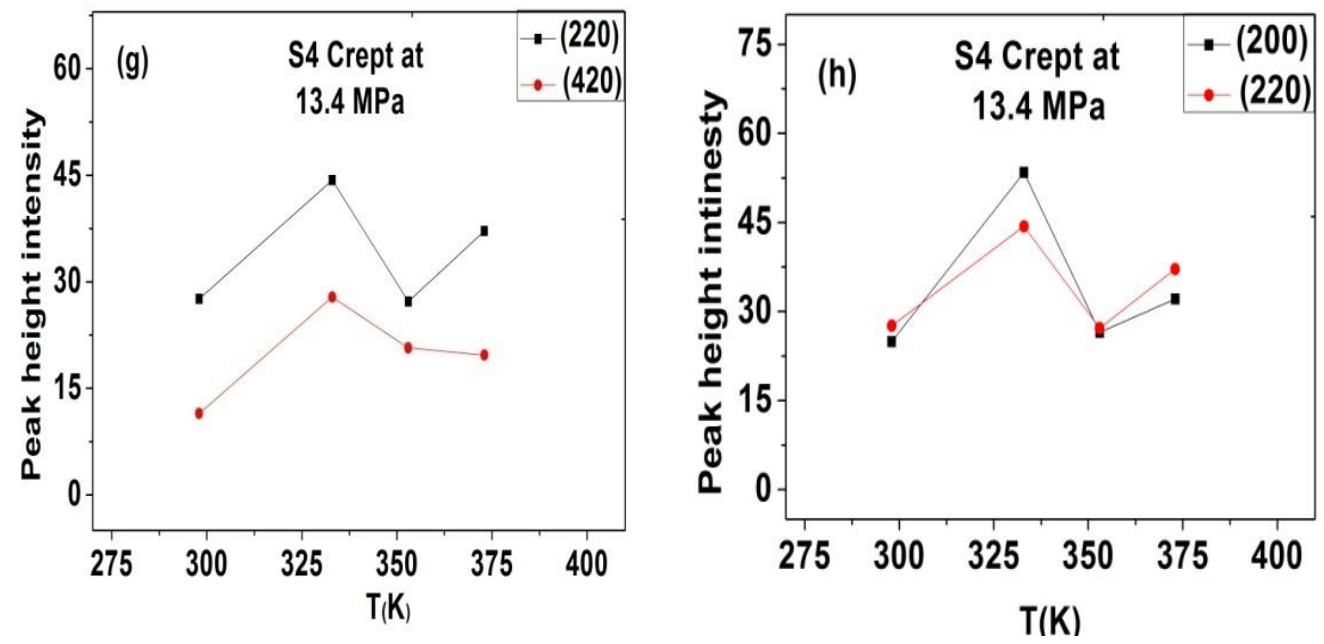

Figure 2(g,h): The intensities of crystallographic planes [(220)\&(420)], [(200)\&(220)] as a function of working temperatures
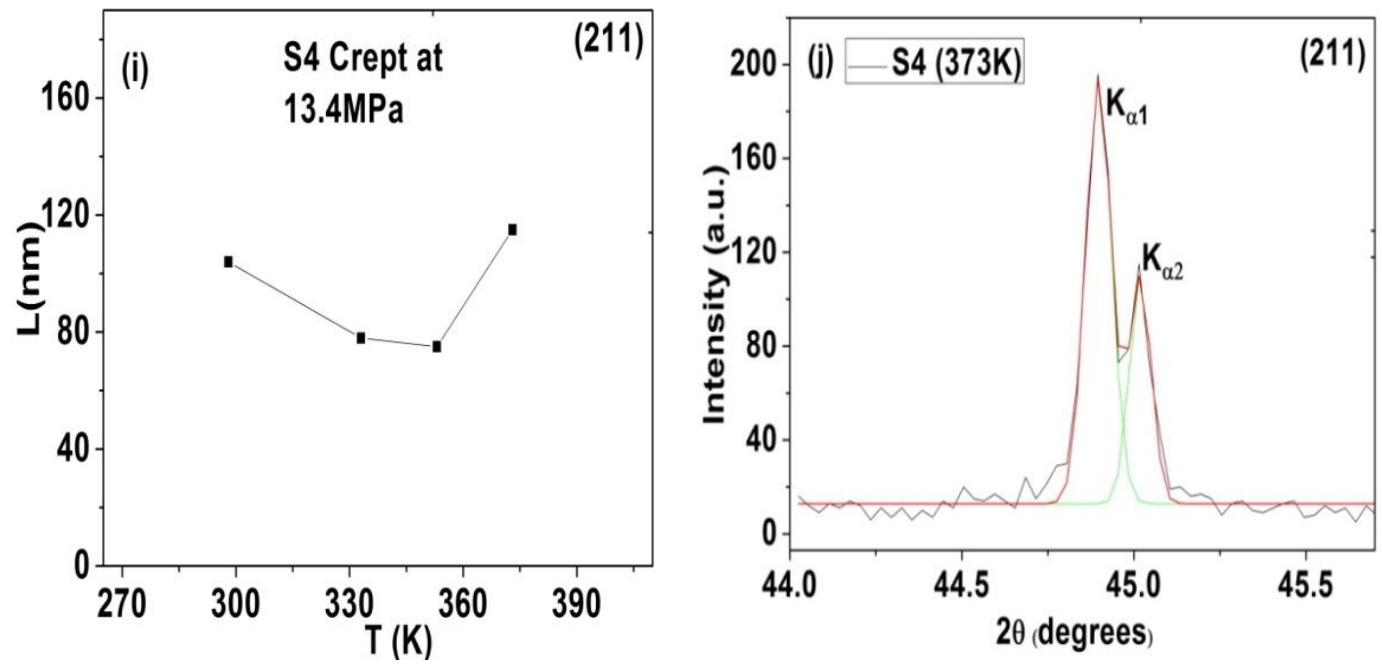

Figure 2:(i) The crystallite size of S4 alloy, (j): Resolution of $\mathrm{K}_{\alpha 1}, \mathrm{~K}_{\alpha 2}$

\subsection{Morphological studies}

Fig. 3(a-d) shows representative SEM of S1, S2, S3, S4 lead free solders. The microstructure of S1 consists of (i) $\mathrm{Ag}_{3} \mathrm{Sn}$ (ii) $\mathrm{Cu}_{6} \mathrm{Sn}_{5}$ (IMCs) inside - - Sn matrix. The magnified micrograph [Fig. 3(e)] represents an eutectic region in the $\mathrm{S} 2$ solder. 


\section{《(ब, $\rfloor$}
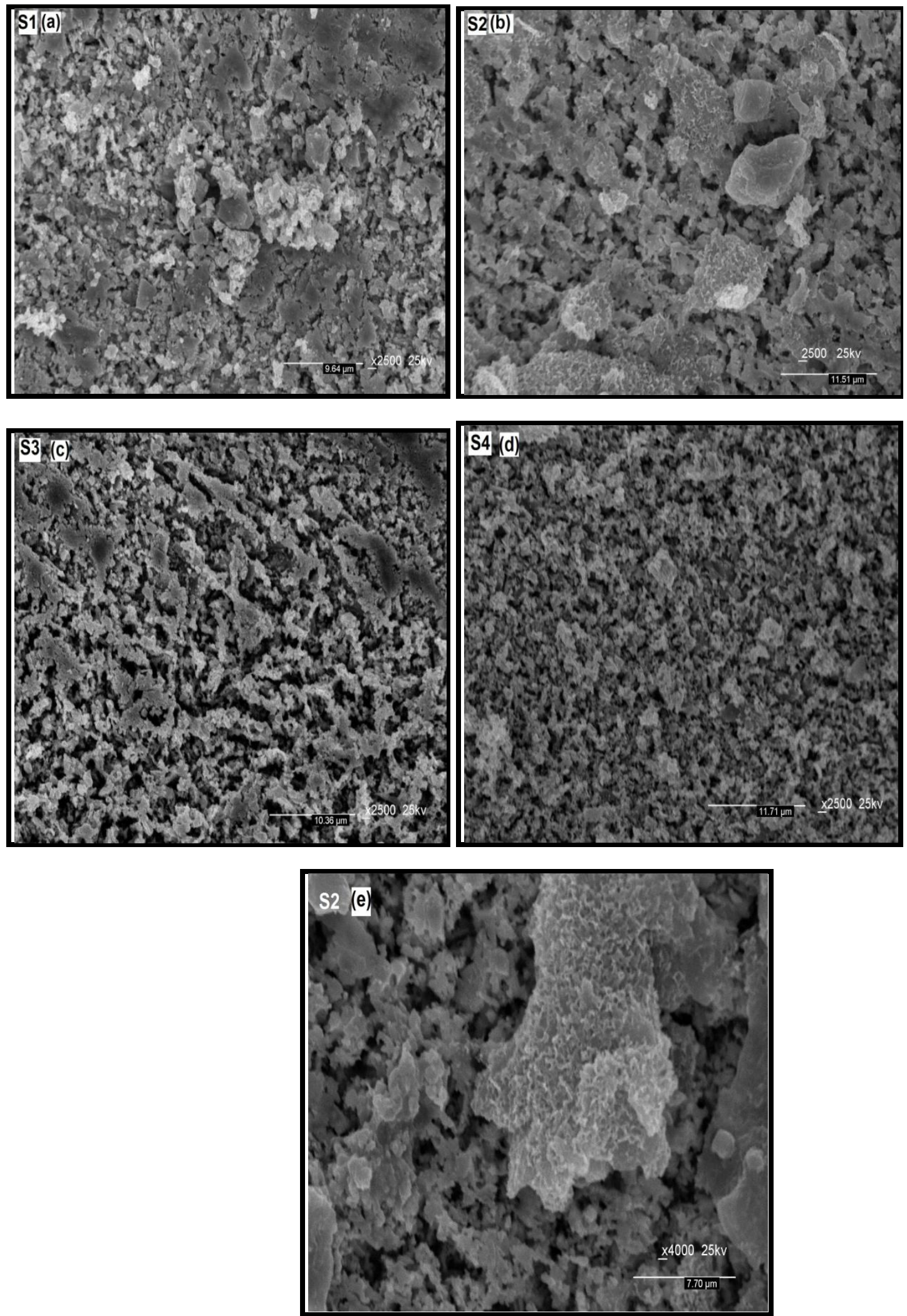

Figure $3(a, b, c, d, e)$ : Scanning electron microscope of S1, S2, S3, S4 alloys and magnified micrograph of S2 


\section{3. Creep Properties}

\section{3.1. Creep features of solder alloys}

Tensile creep curves for the four alloy samples were studied at working temperatures in the range (298 - 373K) and different applied stresses (13.4 - 25.6 MPa). Fig. 4(a-d) shows creep curves of samples tested at room temperature (as an example). The shapes of the curves are conventional.
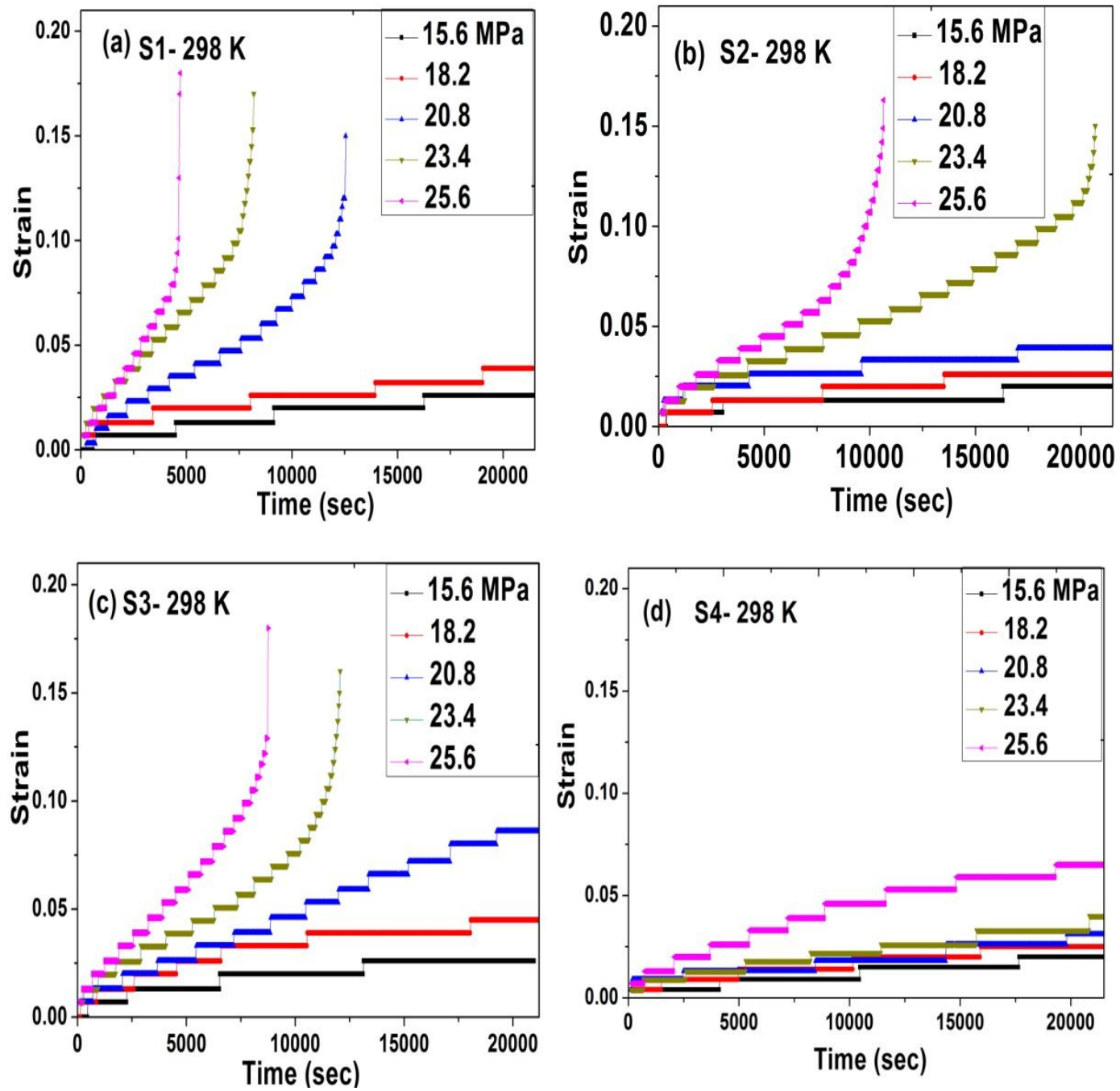

Figure 4 (a,b,c,d): Creep behavior of S1, S2, S3, S4 solder materials at $298 \mathrm{~K}$ and different applied stresses

Typical creep strain - time curves of S1, S2, S3, S4 solder alloys crept at constant applied stress $25.6 \mathrm{MPa}$ at working temperatures of $298 \mathrm{~K}$ are represented in Fig. 4(e). 


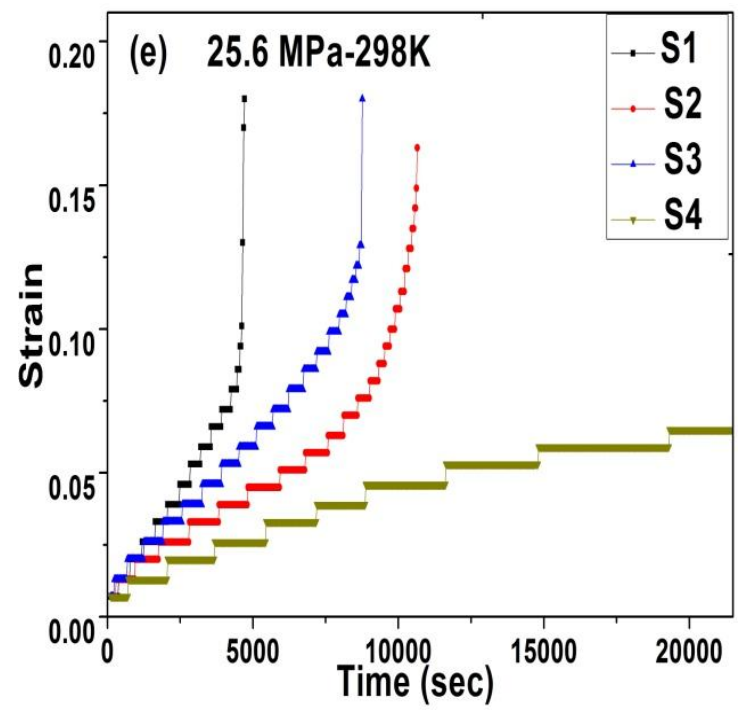

Figure 4 (e): Creep behavior of S1, S2, S3, S4 solder materials at (298K) and constant applied stress (25.6 MPa)

It can be seen that both the creep strain rate and rupture time in the figures are sensitive to the stress level and $\mathrm{Ti}$ additions. Comparing the four solder alloys the creep strain rates $\varepsilon^{\bullet}$ decrease and the creep rupture times $t_{f}$ increase significantly with addition of $\mathrm{Ti}$ - element at a certain stress level expect S3. The important observation made during these tensile creep tests is that the lowest creep rate occurred with the S4 followed by S2, S3 then S1 solder samples. To inspect the effect of Ti-addition on creep performance, the creep curves of the four alloys are given in Fig 4(e). The computed creep strain rate $\varepsilon^{\bullet}$ as a function of time (sec) \& creep strain - at $298 \mathrm{~K}$ and applied stress of $25.6 \mathrm{MPa}$ are given in Fig. $4(\mathrm{f}, \mathrm{g})$. It was found that the creep resistance of S4 solder has much more creep resistance than S1 solder (400\%), the creep resistance of S2 is (230\%) higher than S1, whereas for S3 solder alloy, the creep resistance is (150\%) larger than S1. The results show that creep resistance increases with Ti-additions except for $\mathrm{S} 3$; this is due to the decrease of the amount of $\mathrm{Cu}_{6} \mathrm{Sn}_{5}$ (IMC) and the increase in the eutectic phase $\mathrm{Ag}_{3} \mathrm{Sn}$ which is confirmed by XRD [Fig. 1(a)]. These results are expected for all temperature ranges and applied stresses [Fig. 4(h) is taken as an example]. Fig. 4(i) shows the effect of working temperature on S4 crept at $13.4 \mathrm{MPa}$ (as an example).
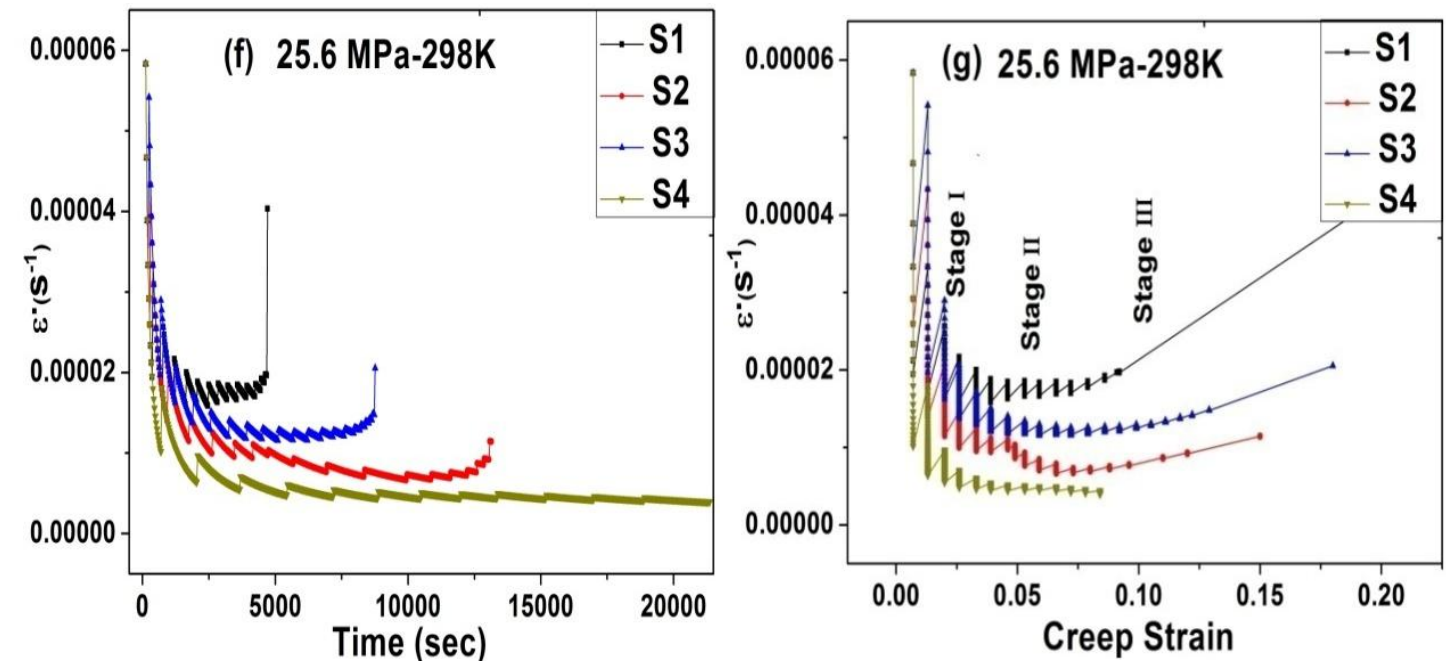

Figure $4(f, g)$ : Creep rate - time and strain relationships 


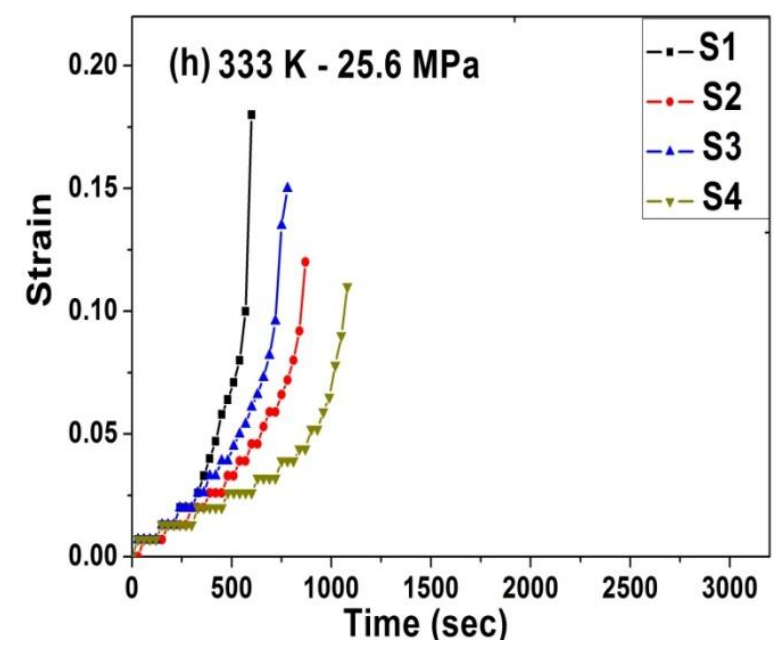

Figure 4 (h): Creep behavior of S1, S2, S3, S4 solder materials at (333K) and constant applied stress (25.6 MPa)

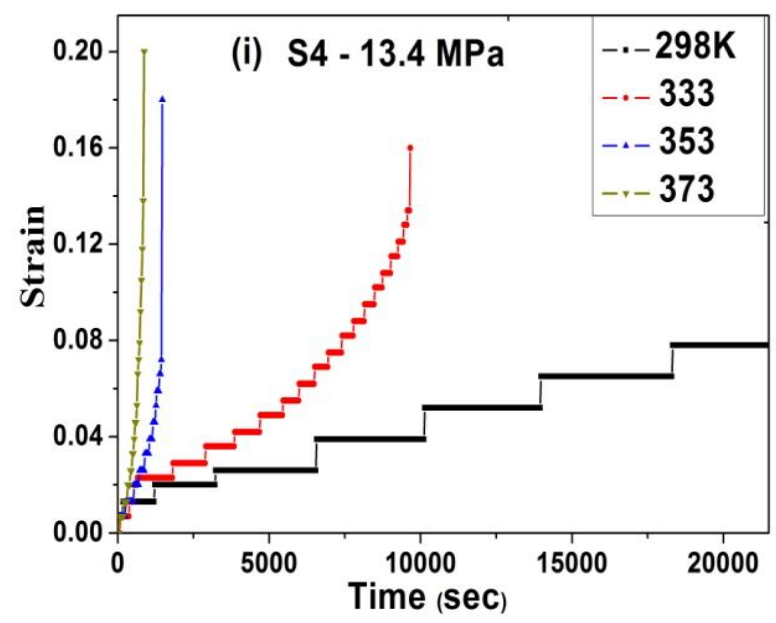

Figure 4 (i): Creep behavior of S4 solder alloy crept at $\cdot=13.4 \mathrm{MPa}$ and at different working temperatures

\section{3. 2. Constitutive creep equation and parameters of lead-free solder alloys}

Previous studies indicated that the dependence of steady state creep rate $\varepsilon_{s}^{\prime}$ on the applied stress $(\sigma)$ and temperature $(T)$ can be expressed as $[24,25]$ :

$\varepsilon_{s}=A \sigma^{n} \exp (-Q / R T)$

Where $\mathrm{A}$ is a complex constant depends on the material structural properties. Taking the natural logarithm on both sides of equation (1), we get:-

$\ln \varepsilon_{s}=\ln A+n \ln \sigma-Q / R T$

It is clear that at a given temperature the creep stress exponent (n) can be calculated by linear regression of the experimental data. Fig. 5 (a-d) show linear relationships between $\left(\ln \varepsilon^{\prime}\right.$ and $\left.\ln \sigma\right)$. 

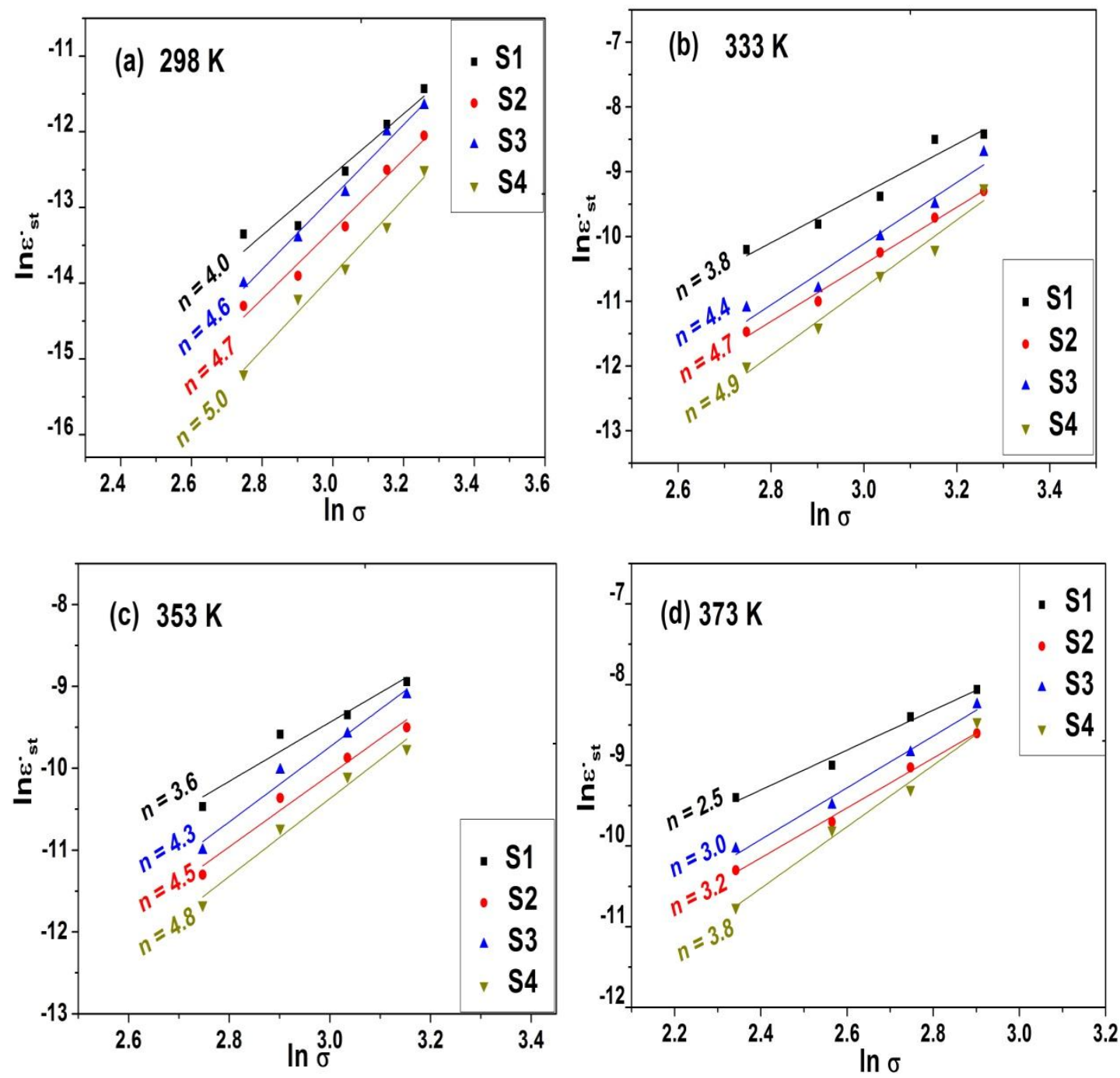

Figure 5 (a, b, c, d): linear relationships between In · and In · for S1, S2, S3, S4 solder alloys for different working temperatures

Results of stress exponent (n) values of the four solders were found to be in the range (2.5 - 5.0). The relation (In $\varepsilon^{\cdot}$ and $\left.1 / T\right)$ is represented in Fig. 6.

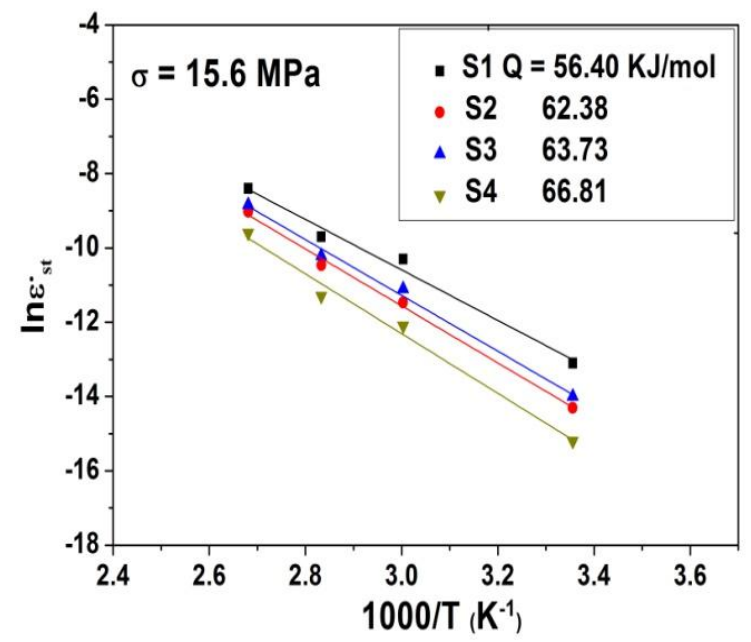

Figure 6: Linear relationships between (Ine· and 1/T) for S1, S2, S3, S4 alloys crept at $15.6 \mathrm{MPa}$ 
The activation energy $(\mathrm{Q})$ value of sample $\mathrm{S} 1$ alloy is $(56.40 \mathrm{KJ} / \mathrm{mol}$.). It is increased to [62.38, 63.73, 66.81 $\mathrm{KJ} / \mathrm{mol}$.] by the addition of the ( $\mathrm{x}-\mathrm{Ti} \mathrm{wt} . \%)$, where $(\mathrm{x}=0.25-1.0 \mathrm{wt} . \%)$. The creep characteristics $(\mathrm{n}$ and $\mathrm{Q})$ values are complied with the reported value of (SnAg) which is controlled by dislocation climb $[24,26]$.

\section{4. Thermal Properties}

A promising solder alloys should have a lower melting temperature and a narrow pastry temperature zone which are very important for electronic applications [27-30]. A typical DSC profile of (S1, S2, S3, S4) alloys upon heating in DSC instrument at a scanning rate of $\left(10^{\circ} \mathrm{C} / \mathrm{min}\right)$ is represented in Fig. $7(\mathrm{a})$.

(a)

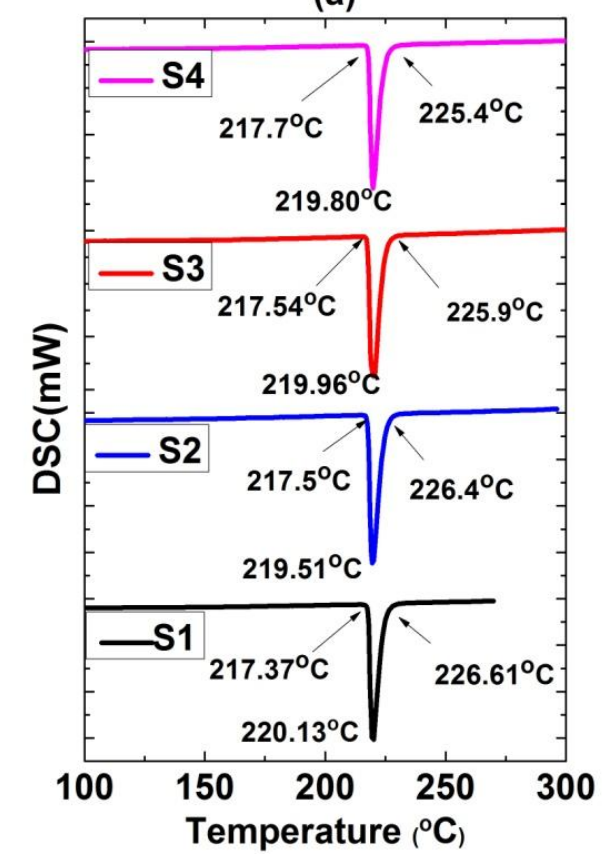

Figure 7(a): DSC profile of S1, S2, S3, S4 alloys.

It is clear that the alloys are characterized by end thermal peaks at $\left(220.13,219.51,219.96\right.$ and $\left.219.8{ }^{\circ} \mathrm{C}\right)$ corresponding to melting temperatures $\left(T_{m}\right)$ for $(S 1, S 2, S 3, S 4)$ alloys respectively. It was found that $T_{m}$ is slightly decreased with the $\mathrm{Ti}$ - addition. Fig. $7(\mathrm{~b})$ shows that the pastry range denoted by $\left(\mathrm{T}_{\text {end }}-\mathrm{T}_{\text {onset }}\right)$ is decreased with the Ti wt\%. additions.

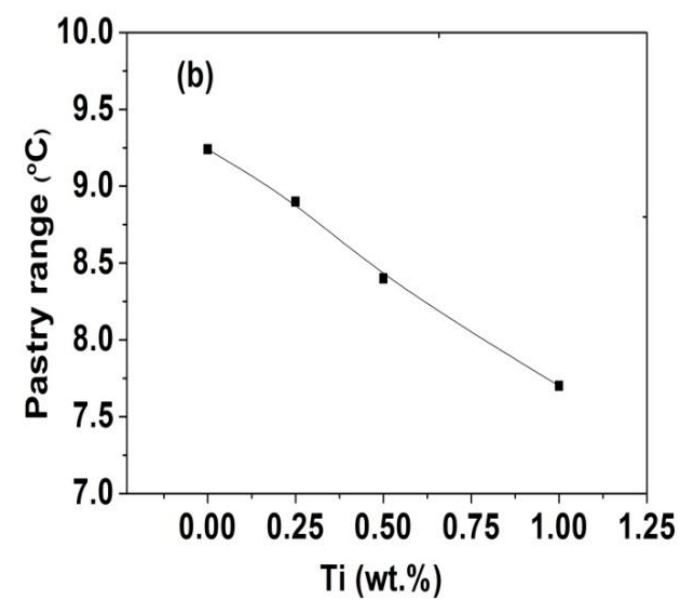

Figure 7(b): The pastry range as a function of Ti wt\%-additions 


\section{Conclusions}

The main conclusions to be drawn from the investigation may be summarized as follows: -

1. From microstructure examination the IMCs are precipitated within the $\beta$-matrix in the based Pb-free solder alloys exhibited additional phases of $\mathrm{Ag}_{3} \mathrm{Sn}, \mathrm{Cu}_{6} \mathrm{Sn}_{5}$ and $\mathrm{Sn}_{2} \mathrm{Ti}_{3}$ (IMCs).

2. X-ray parameters of the crept samples (S4) show anomalous effect at temperature $353 \mathrm{~K}$. due to the increase of the amount of $\mathrm{Cu}_{6} \mathrm{Sn}_{5}$ (IMC).

3. The lattice parameters $a, c, c / a$ of $\beta-S n$ phase are found to change with both Ti wt.\% contents as well as the change of working temperatures.

4. Anomalous behaviors are obtained with adding $0.5 \mathrm{wt}$.\%Ti due to the less amount of the $\mathrm{Cu}_{6} \mathrm{Sn}_{5}$.

5. Ti-addition with 1.0 wt.\% (S4) alloy shows a superior creep behavior compared with the others (S1,S2). This is due to its lower melting temperature and finer microstructure.

6. A significant improvement in the creep resistance is achieved by the addition of Ti to the SnAgCu solder alloy. The addition of $1 \mathrm{wt} . \% \mathrm{Ti}$ and at working temperature $298 \mathrm{~K}$ showed a minimum creep rate up to $\sim 400 \%$. The decrease in creep rates ( $\left.\varepsilon^{\cdot}\right)$ with different Ti\% additions is affected by the volume fraction of $\mathrm{Ag}_{3} \mathrm{Sn}_{1} \mathrm{Cu}_{6} \mathrm{Sn}_{5}$ and $\mathrm{Sn}_{2} \mathrm{Ti}_{3}$ (IMCs).

7. The Sn-3.5wt.\%Ag-0.5wt.\%Cu-1.0wt.\%wt.\%Ti proved to be a promising solder, since it has a good contribution of higher creep resistance and fracture time than the others.

8. The addition of $0.5 \mathrm{wt}$.\%Ti shows less hardening due the less amount of $\mathrm{Cu}_{6} \mathrm{Sn}_{5}$, which is confirmed by XRD analysis.

9. The obtained ( $n$ and $Q$ ) values suggested that the creep of the four alloys is dominated by climb dislocation.

10. Addition of Ti-element to the $\mathrm{SnAgCu}$ alloy shows a slight improvement in melting temperature and decreases in pastry range.

\section{References}

1. K.S. Kim, S.H. Huha, K. Suganuma, "Effects of intermetallic compounds on properties of Sn-Ag-Cu lead-free soldered joints, "Journal of Alloys and Compounds 352 (2003) 226-236.

2. K.Swiese, J.Wolter, "Microstructure and creep behavior of eutectic SnAg and SnAgCu solders", Microelectronic Reliability, 44 (2004) 1923-1931.

3. A.M. Yassin, E. Gomaa, "The study of microstructure and creep properties of Cu-doped Sn-4wt\%Ag and Sn9wt\%Zn lead free solders with annealing temperature", Physics Journal, 1 (2015) 163-172.

4. L. Gao, S. Xue, L. Zhang, Z. Sheng, F. Ji, W. Dai, S. Yu, G. Zeng, "Effect of alloying elements on properties and microstructures of SnAgCu solders", Microelectron. Eng. 87 (2010) 2025-2034.

5. L.C. Tsao, S.Y. Chang, Mater. Des. 31 (2010) 990-993.

6. L.C. Tsao, "An investigation of microstructure and mechanical properties of novel Sn3.5Ag0.5Cu-XTiO2 composite solders as functions of alloy composition and cooling rate", Mater. Sci. Eng. A 529 (2011) 41-48.

7. L.C. Tsao, S.Y. Chang, C.I. Lee, W.H. Sun, C.H. Huang, Mater. Des. 31 (2010) 4831-4835.

8. T.H. Chuang, M.W. Wu, S.Y. Chang, S.F. Ping, L.C. Tsao, J. Mater. Sci. Mater. Electron. 22 (2011) 1021-1027. 
9. P. Liu, P. Yao, J. Liu, J. Electron. Mater. 37 (2008) 874-879.

10. A.K. Gaina, T. Fouzdera, Y.C. Chana, W.K.C. Yung, J. Alloys Compd. 509 (2011) 3319-3325.

11. Y. Tang, G.Y. Li, Y.C. Pan, " Effects of TiO2 nano-particles addition on microstructure, microhardness and tensile properties of Sn-3.0Ag-0.5Cu-xTiO2 composite solder", Materials and Design 55 (2014) 574-582.

12. S.Y. Chang, C.C. Jain, T.H. Chuang, L.P. Feng, L.C. Tsao, "Effect of addition of TiO2 nano-particles on the microstructure, microhardness and interfacial reactions of Sn3.5AgXCu solder", Materials and Design 32 (2011) 4720-4727.

13. D.Q. Yu, J. Zhao, L. Wang, J. Alloys Compd. (2004) 170-175.

14. C.M.L. Wu, D.Q. Yu, C.M.T. Law, L. Wang, Mater. Sci. Eng. R 44 (2004) 1-44.

15. Tama Fouzder, Ismathullakhan Shafiqa, Y.C. Chana, A. Sharif, Winco K.C. Yung, "Influence of SrTiO3 nanoparticles on the microstructure and shear strength of $\mathrm{Sn}-\mathrm{Ag}-\mathrm{Cu}$ solder on $\mathrm{Au} / \mathrm{Ni}$ metallized $\mathrm{Cu}$ pads", Journal of Alloys and Compounds 509 (2011) 1885-1892.

16. A.E. Hammad, "Evaluation of microstructure, thermal and creep properties of Ni-doped $\mathrm{Sn}-0.5 \mathrm{Ag}-0.7-\mathrm{Cu}$ low Ag solder alloys for electronic applications", Materials and Design, 52 (2013) 663-670.

17. F.Cheng, H. Nishikawa, T. Takemoto, "Microsturcture and mechanical properties of Sn-Ag-Cu lead free solders with minor addition of $\mathrm{Ni}$ and /or Co", J. Mater Sci. 8 (2008) 3643-3648.

18. CK. Chung, Tc. Huang, R. Shia, TL. Yang, CR. Kao, "Roles of phosphorous in Sn4Ag0.5Cu solder reaction with electrolyic Ni-Au", J. Alloy Compd. 539, (2012) 57-62.

19. AA. El-Daly, AE. Hammad, A. Fawzy, DA. Nasrallh, "Microstructure, mechanical properties and deformation behavior of Sn-10Ag-0.5Cu solder after Ni and Sb additions", Material Design 43 (2013) 40-49.

20. L. Gao, S. Xue, L. Zhang, Z. Sheng, F. Ji, W.Dai,"Effect of alloying elements on properties and microstructures of SnAgCu solders", Microelectron Eng., 87 (2010) 2025-2034.

21. C.L. Chuang, L.C. Tsao, H.K. Lin, L.P. Feng, "Effects of small amount of active Ti element additions on microstructure and property of Sn3.5Ag0.5Cu solder", Materials Science \& Engineering A 558 (2012) 478 - 484.

22. W. Liu, P. Bachorik, N.C. Lee, IEEE Electron. Compon. Technol. Conf. 58 (2008) 452.

23. W.M. Chen, S.K. Kang, C.R. Kao, J. Alloys Compd. 520 (2012) $244-249$.

24. B.A. Khalifa, R. Afify Ismail, A. M. Yassin, "Structure Analysis, Enhancement of Creep Resistance and Thermal Properties of Eutectic Sn-Ag Lead-Free Solder Alloy by Ti and Cd Additions", Journal of advance physics, 13, 8 (2017) 2347-2387.

25. A.A. El-Daly, "Tensile properties of Pb-Sn bearing alloy containing small amount of Sb", Phys. Stat. Sol. A 201 (2004) 2035-2041.

26. D. Witkin, "Creep behavior of Bi- containing lead free solder alloy", J. Electron Mater .41, 2 (2012) 190-203.

27. P.Babaghorbani, S.M.L. Nai, M. Gupta, "Development of lead free Sn-3.5Ag/SnO ${ }_{2}$ nanocomposite solder" Journal of Material Science, Mater Electron, 20 (2009) 571-576.

28. A .Haseeb, M.M. Arafat, and M.R. Johan, "Stability of Molybdenum nanoparticles Sn-3.8Ag-0.7Cu solder during multiple reflow and their influence on interfacial intermetallic compounds", Journal of Materials Characterization 64 (2012) 27-35. 
29. A.A .El-Daly, A.E. Hammad, G.S. Al-Ganainy, and M. Ragab, "Properties enhancement of low Ag-content Sn-AgCu lead-free solders containing small amount of Zn", Journal of Alloys and Compounds, 614 (2014) 20-28.

30. A.A. El-Daly, A.E. Hammad, G.S. Al-Ganainy, and A.A. Ibrahiem, "Design of lead-free candidate alloys for low temperature soldering application based on the hypoeutectic Sn-6.5Zn alloys", Materials and Design 56 (2014) 594-603. 